\title{
Pelatihan Senam Neuromove Sebagai Upaya Peningkatan Pengetahuan dan Pencegahan Neuropati Perifer Diabetika Kader Kesehatan RT 3 RW 1 Desa Menganti Kabupaten Cilacap
}

\author{
Arief Hendrawan $^{1}$ \\ ${ }^{1}$ Prodi D3 Fisioterapi \\ STIKES Al-Irsyad Al-Islamiyyah, Jalan Cerme No 24 Sidanegara Cilacap 53223 \\ Email korespondensi: hendrarie@gmail.com
}

\begin{abstract}
Abstrak
Neuropati Perifer Diabetika (NPD) adalah istilah yang digunakan untuk kondisi-kondisi yang terkait dengan gangguan fungsi saraf. Gejala umum dari neuropati adalah kram, kaki kesemutan dan baal (mati rasa). Neuropati perifer diabetik (NPD) adalah suatu keadaan dimana didapatkan kelainan klinik maupun sub klinik yang ditandai dengan adanya manifestasi somatik dari sistem saraf perifer pada penderita diabetes melitus tanpa adanya penyebab lain dari neuropati perifer. Terapi pada kondisi NPD dapat bersifat farmakologi (obat) maupun non farmakologi (tanpa obat). Penggunaan obat-obatan dan vitamin dapat mengurangi keluhan pada NPD. Latihan fisik yang teratur juga mampu untuk mengatasi kondisi NPD. Latihan aerobik dan peregangan mampu untuk mengatasi keluhan nyeri perifer pada penderita diabetes. Bentuk kegiatan pengabdian adalah penyuluhan dan pelatihan. Materi kegiatan meliputi definisi NPD, tanda dan gejala NPD, pencegahan NPD, obat-obatan untuk kondisi NPD dan pelatihan senam neuromove. Target kegiatan pengabdian : peningkatan pengetahuan kader kesehatan serta warga masyarakat tentang NPD dan peningkatan ketrampilan tentang latihan fisik (senam neuromove) untuk mengatasi keluhan NPD. Hasil dari kegiatan pengabdian ini didapatkan peningkatan pengetahuan kader kesehatan tentang kondisi NPD sebesar $82 \%(\mathrm{n}=25)$ dan didapatkan peningkatan ketrampilan tentang senam neuromove.
\end{abstract}

Keywords: neuropati, diabetes, senam

\begin{abstract}
Diabetic peripheral neurophaty (NPD) is a term used for conditions associated with impaired nerve function. Common symptoms of neurophaty are cramps, tingling leg and numbness). Diabetic peripheral neurophaty (NPD) is a condition in which clinical or sub clinical abnormalities are indicated by presence of somatic manifestations of peripheral-laden systems in people with diabetes mellitus without other causes of peripheral neurophaty. Therapy in NPD conditions can pharmacological (drug) or non-pharmacologycal (without drugs). The use of drug and vitamins can reduce complaints on NPD. Regular physical exercise is also able to overcome the NPD condition. Aerobic exercise and stretching are able to overcome complaints of peripheral pain in diabetic. The form of community service activities is counseling and training. Activities include NPD definition, NPD signs and symptoms, NPD prevention, drugfor NPD condition and neuromove training. Target of community service activities : increasing the knowledge of health cadres and community members about NPD and increasing skills in physical exercise (neuromoce training) to overcome NPD complaints. The results of this community service activity showed an increase in the knowledge of health cadres about NPD condition by $82 \%(n=25)$ and an increase in skills regarding neuromove gymnastics.
\end{abstract}

Keywords: neuropathy, diabetic, training 


\section{PENDAHULUAN}

Kondisi nyeri sering diutarakan oleh masyarakat dalam praktik klinik. Salah satu kondisi nyeri yang sering disampaikan adalah nyeri pada daerah perifer (ujung/tepi). Dalam istilah medik kondisi ini dinamakan neuropati perifer. Neuropati adalah istilah yang digunakan untuk kondisi-kondisi yang terkait dengan gangguan fungsi saraf. Kondisi neuropati sering dijumpai pada penderita diabetes mellitus (Suyanto \& Susanto, 2016). Gejala umum dari neuropati adalah kram, kaki kesemutan dan baal (mati rasa) (Sativa, 2013)

Neuropati perifer diabetik (NPD) adalah suatu keadaan dimana didapatkan kelainan klinik maupun sub klinik yang ditandai dengan adanya manifestasi somatik dari sistem saraf perifer pada penderita diabetes melitus tanpa adanya penyebab lain dari neuropati perifer (Aprinda, 2020). Frekuensi terjadinya NPD di masyarakat cukup tinggi. Terlapor $50 \%$ dari penderita diabetik di Indonesia mengeluhkan adanya nyeri perifer (Anonim, 2015a) Keluhan utama (subyektif) yang paling banyak diutarakan adalah rasa kram / gangguan sensasi pada kedua kaki (Anonim, 2015c; Suyanto, 2017).

Terapi pada kondisi NPD dapat bersifat farmakologi (obat) maupun non farmakologi (tanpa obat). Penggunaan obat-obatan dan vitamin dapat mengurangi keluhan pada NPD. Tindakan non farmakologis yang dapat dilakukan untuk mengurangi keluhan pada penderita neuropati perifer adalah dengan latihan fisik.

Latihan fisik yang teratur juga mampu untuk mengatasi kondisi NPD (Anonim, 2015b). Latihan aerobik dan peregangan mampu untuk mengatasi keluhan nyeri perifer pada penderita diabetes (Sukmasari, 2016). Latihan senam kaki juga bermanfaat mengatasi keluhan pada penderita neuropati perifer diabetika (Haris, Indirawaty, \& Askar, 2018).

\section{MASALAH}

Permasalahan yang dihadapi Mitra adalah masih rendahnya pengetahuan kader kesehatan tentang kondisi Neuropati Perifer Diabetika (NPD), masih rendahnya pengetahuan dan ketrampilan kader kesehatan tentang olahraga (senam) untuk mencegah dan mengurangi gangguan fisik (nyeri) kondisi Neuropati Perifer Diabetika (NPD). Berdasarkan permasalahan tersebut, tim pengabdian mengadakan 
kegiatan peningkatan pengetahuan kader kesehatan tentang kondisi Neuropati Perifer Diabetika (NPD) dan peningkatan ketrampilan kader kesehatan tentang olahraga (senam) untuk mencegah dan mengurangi gangguan fisik (nyeri) kondisi Neuropati Perifer Diabetika (NPD).

\section{METODE}

Pengabdian kepada masyarakat ini dilaksanakan di RT 3 RW 1 Desa Menganti Kecamatan Kesugihan Kabupaten Cilacap. Sasaran kegiatan adalah kader kesehatan dan warga RW 1 Desa Menganti. Adapun metode pelaksanaannya adalah :

\section{1) Kegiatan Pelatihan}

Kegiatan pelatihan dilakukan kepada Kader Kesehatan RT 3 RW 1 Desa Manganti Cilacap dengan materi pelatihan senam Neuromove. Peserta pelatihan akan mendapatkan materi (modul) dan pelatihan (praktik) senam Neuromove. Media yang digunakan adalah peralatan senam dan buku tutorial senam. Pelatihan dilakukan sebanyak 3 kali.

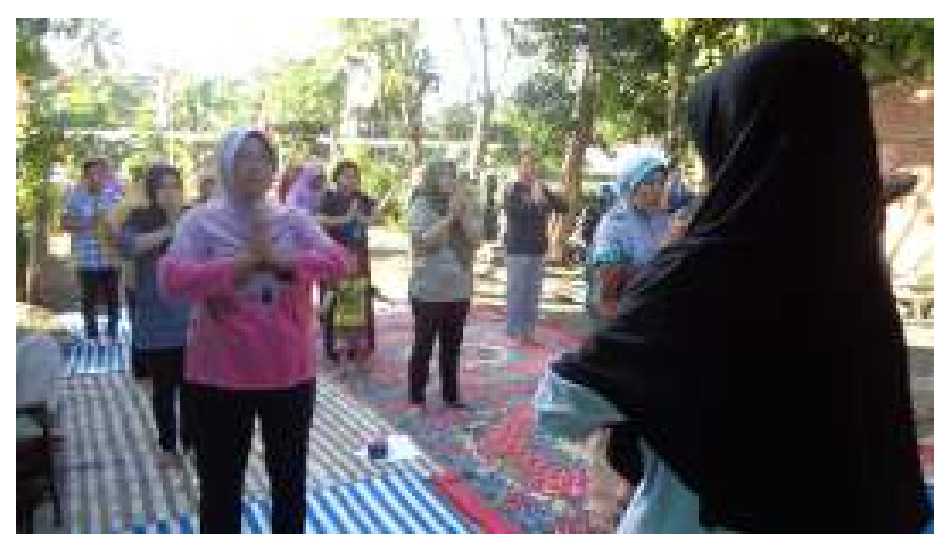

Gambar 1. Pelaksanaan Senam Neuromove (Dokumen Pribadi)

2) Kegiatan Penyuluhan

Kegiatan penyuluhan dilakukan kepada Kader Kesehatan RT 3 RW 1 Desa Menganti Cilacap oleh tim pengabdian. Kader kesehatan akan mendapatkan materi penyuluhan tentang definisi penyakit, obat dan vitamin untuk mengatasi NPD, senam neuromove untuk mencegah dan mengurangi nyeri kondisi NPD. Kegiatan penyuluhan akan dilakukan sebanyak 2 kali. Sebelum dilakukan pemaparan materi, kader kesehatan akan diminta untuk mengisi kusioner awal (pre-test). Sesudah 
kegiatan penyuluhan selesai, kader akan diminta kembali mengisi kuesioner akhir (post-test).

Adapun gambaran umum pelaksanaan kegiatan pengabdian ini adalah sebagai berikut :

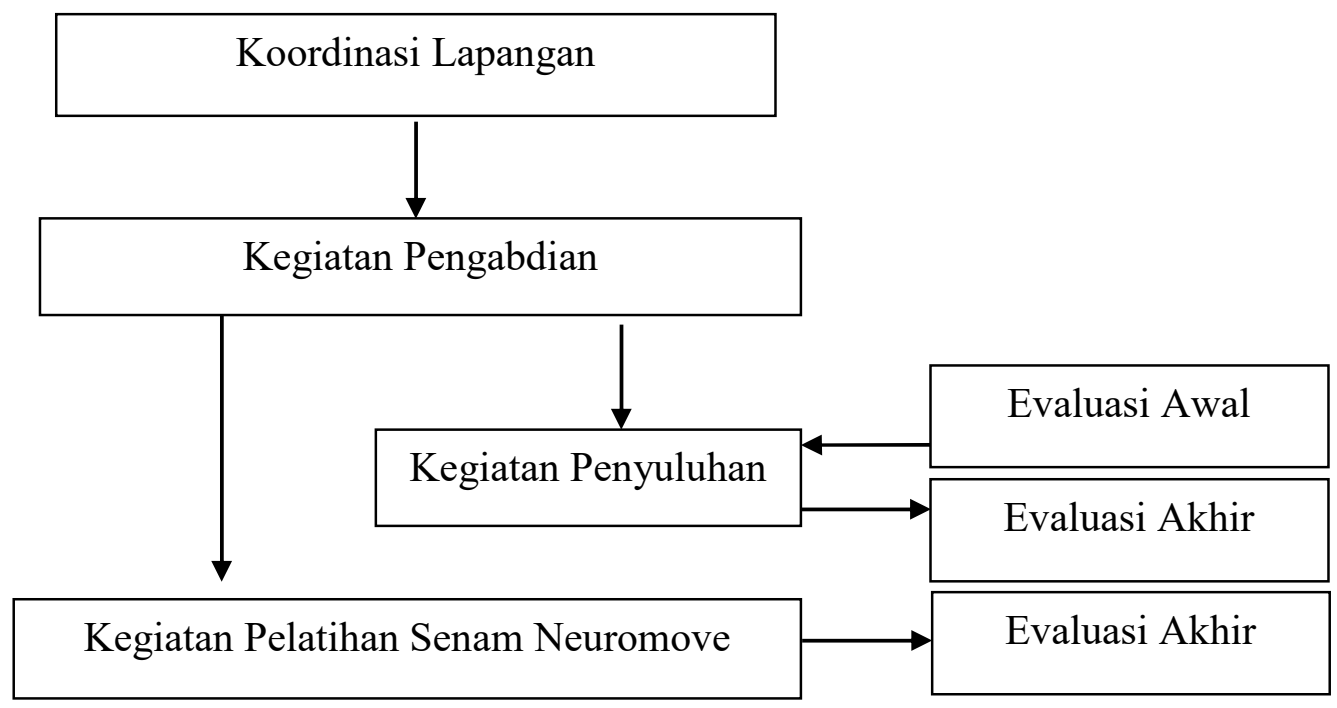

Gambar 2. Bagan Pelaksanaan Kegiatan Pengabdian

\section{HASIL DAN PEMBAHASAN}

Hasil dan pembahasan kegiatan pengabdian adalah sebagai berikut :

\section{1) Hasil}

Kegiatan pengabdian diikuti oleh 25 orang peserta. Setiap peserta mengisi kuesioner yang telah disiapkan oleh tim pengabdian. Setiap peserta mengisi kuesioner sebelum dan sesudah kegiatan berlangsung. Kuesioner diberikan untuk mengukur tingkat kemampuan peserta dalam memahami materi tentang Neuropati Perifer Diabetika (NPD). Dari pelaksanaan evaluasi tingkat pengetahuan peserta didapatkan hasil sebagai berikut :

Tabel 1. Tingkat Pengetahuan Peserta Sebelum Kegiatan

\begin{tabular}{cccc}
\hline Peserta & Kriteria Nilai & Persentase Nilai & Rerata (\%) \\
\hline $\mathrm{n}=25$ & Rendah & 53,85 & 41,6 \\
& Sedang & 46,15 & \\
\hline
\end{tabular}

Sumber Data Primer, 2019

Tabel 2. Tingkat Pengetahuan Peserta Setelah Kegiatan

\begin{tabular}{cccc}
\hline Peserta & Kriteria Nilai & Persentase Nilai & Rerata (\%) \\
\hline $\mathrm{n}=25$ & Sedang & 17,07 & 82 \\
& Tinggi & 82,93 & \\
\hline Sumber Data Primer, 2019 & &
\end{tabular}

Sumber Data Primer, 2019 
Sedangkan dari evaluasi tingkat ketrampilan peserta didapatkan hasil :

Tabel 3. Tingkat Ketrampilan Peserta Sebelum Kegiatan

\begin{tabular}{cccc}
\hline Peserta & Kriteria Nilai & Persentase Nilai & Rerata (\%) \\
\hline $\mathrm{n}=25$ & Rendah & 12,98 & 41 \\
& Sedang & 85,58 & \\
\hline
\end{tabular}

Sumber Data Primer, 2019

Tabel 4. Tingkat Ketrampilan Peserta Setelah Kegiatan

\begin{tabular}{cccc}
\hline Peserta & Kriteria Nilai & Persentase Nilai & Rerata (\%) \\
\hline $\mathrm{n}=25$ & Sedang & 45,70 & 76,6 \\
& Tinggi & 54,30 & \\
\hline
\end{tabular}

Sumber Data Primer, 2019

\section{2) Pembahasan}

Pengabdian masyarakat dilaksanakan selama 5 kali. Kegiatan pertama dan kedua adalah pemberian materi tentang neuropatik perifer diabetika (meliputi penyebab, tanda dan gejala) dan obat-obatan untuk neuropatik perifer diabetik yang dapat dicari tanpa menggunakan resep dokter. Kegiatan ketiga sampai kelima adalah pelatihan senam neuromove. Sebelum dilakukan kegiatan penyuluhan dan kegiatan pelatihan, terlebih dahulu peserta pelatihan diukur tingkat pengetahuannya.

Pengukuran tingkat pengetahuan menggunakan kuesioner yang harus dijawab oleh peserta. Pengukuran tingkat pengetahuan dilaksanakan sebelum (pre-test) dan sesudah (post-test) kegiatan penyuluhan. Tingkat pengetahuan peserta sebelum kegiatan tampak pada tabel 1. Pada tabel tersebut tampak tingkat pengetahuan peserta sebesar 53,85\% (kategori rendah) dan sebesar 46,15\% (kategori sedang). Rerata tingkat pengetahuan peserta sebelum kegiatan sebesar 41,6\%. Hal ini menunjukkan bahwa tingkat pengetahuan peserta sebelum kegiatan tergolong rendah. Setelah dilakukan pengukuran tingkat pengetahuan peserta sebelum kegiatan maka dilanjutkan dengan pemberian materi penyuluhan. Materi penyuluhan meliputi pembahasan mengenai definisi penyakit NPD, tanda dan gejala NPD dan tindakan pengobatan pada kondisi NPD. Dalam kegiatan penyuluhan ini diadakan juga kegiatan interaktif berupa tanya jawab antara peserta kegiatan dengan pemateri. Seteleh kegiatan penyuluhan selesai dilaksanakan maka peserta kegiatan diukur kembali tingkat pengetahuannya. Hasil tingkat kemampuan peserta tampak pada tabel 2. Pada tabel tersebut tingkat pengetahuan peserta 17,07\% (kategori sedang) dan 82,93\% (kategori tinggi). Rerata tingkat kemampuan 
peserta sesudah kegiatan $82 \%$. Hal ini tampak terjadi peningkatan tingkat kemampuan peserta. Tingkat kemampuan peserta meningkat karena peserta lebih memahami tentang kondisi yang dibahas. Peserta kegiatan juga terlibat secara aktif dalam kegiatan diskusi dan tanya jawab.

Pada pelaksanaan kegiatan pelatihan senam, peserta kegiatan juga diukur tingkat ketrampilannya sebelum dan sesudah mengikuti kegiatan. Pengukuran praktik menggunakan instrument penilaian ketrampilan. Tingkat ketrampilan peserta sebelum kegiatan tampak pada tabel 3. Pada tabel tersebut tingkat ketrampilan peserta sebesar 12,98\% (kategori rendah) dan 85,58\% (kategori sedang). Rerata tingkat kemampuan sebelum kegiatan sebesar 41\%. Setelah diberikan jeda latihan senam didapatkan peingkatan ketrampilan menjadi 45,70\% (kategori sedang) dan 54,30\% (kategori tinggi). Rerata tingkat ketrampilan setelah kegiatan adalah 76,6\% (tabel 4.4). Dari sini tampak terjadi peningkatan tingkat ketrampilan dari peserta. Peningkatan tingkat ketrampilan ini karena peserta lebih memahami konsep dasar senam dan melakukan kegiatan senam secara mandiri sehingga peserta menjadi lebih hafal terhadap gerakan-gerakan yang dilakukan saat senam.

\section{KESIMPULAN}

Kesimpulan kegiatan pengabdian ini adalah meningkatnya pengetahuan kader kesehatan tentang kondisi Neuropati Perifer Diabetika (NPD), meningkatnya pengetahuan dan ketrampilan kader kesehatan tentang olahraga (senam) untuk mencegah dan mengurangi gangguan fisik (nyeri) kondisi Neuropati Perifer Diabetika (NPD).

\section{DAFTAR PUSTAKA}

Anonim. (2015a). Neuropati Perifer. Retrieved from www.rsseejahterabhakti.com/2015/01/neuropati-perifer/

Anonim. (2015b). Olahraga Ini Bantu Cegah Kerusakan Saraf Tepi. Retrieved from www.health.kompas.com

Anonim. (2015c). Penyakit Nyeri Neuropatik. Retrieved from www.referensisehat.com/2015/03/25/Penyakit-Nyeri-Neuropatik 
Aprinda, P. (2020). Neuropati Diabetik. Retrieved from https://hellosehat.com/kesehatan/penyakit/neuropati-diabetik-adalah/

Haris, M., Indirawaty, \& Askar, M. (2018). Pengaruh Senam Kaki Diabetik Terhadap Sensitivitas Neuropati Perifer Pada Penderita Diabetes Melitus Tipe II Di Puskesmas Mangasa Kota Makassar. Jurnal Luka Indonesia.

Sativa, R. . (2013). Neuropati Bisa Dicegah Tapi Kenali Gejalanya Dulu. Retrieved from detikhealth.com website: www.detikhealth.com

Sukmasari, R. . (2016). Olahraga Seperti Ini Dianjurkan untuk Bantu Cegah Terjadinya Neuropati. Retrieved from 2016 website: www.detikhealth.com

Suyanto. (2017). Gambaran Karakteristik Penderita Neuropati Perifer Diabetik. Nurscope, Jurnal Keperawatan Dan Pemikiran Ilmiah.

Suyanto, \& Susanto, A. (2016). Faktor-Faktor yang Berhubungan dengan Kejadian Neuropati Perifer Diabetik. Jurnal Keperawatan Dan Pemikiran Ilmiah. 